\title{
Effect of Bronsted Base on Topological Alteration of Rice Husk as an Efficient Adsorbent Comparative to Rice Husk Ash for Azo Dyes
}

\author{
Rahat Naseer $^{1 *}$, Nargis Afzal ${ }^{2}$, Zulfiqar-ul-Hassan ${ }^{3}$, Shagufta Saeed ${ }^{1}$, Huma Mujhahid ${ }^{1}$, \\ Sherish Faryal', Sadaf Aslam ${ }^{4}$, Habib-ur-Rehman ${ }^{5}$ \\ ${ }^{1}$ Institute of Biochemistry and Biotechnology, University of Veterinary and Animal Sciences, Lahore, Pakistan \\ ${ }^{2}$ Central Laboratory Complex, University of Veterinary and Animal Complex, Lahore, Pakistan \\ ${ }^{3}$ Department of Pharmacology, Central Park Medical College \\ ${ }^{4}$ Department of Clinical Medicine and Surgery, UVAS, Lahore, Pakistan \\ ${ }^{5}$ Department of Physiology, the University of Veterinary and Animal Sciences, Lahore, Pakistan
}

Received: 19 July 2019

Accepted: 14 September 2019

\begin{abstract}
Rice husk (RH) is a notable fraction of lingo-cellulosic waste of paddy rice, abundantly available in rice-producing countries. In the last few years, rice husk ash, one of the processed products of the husk, has gained attention as an adsorbent. The present study the first time elucidates the adsorption kinetics of sodium hydroxide-treated rice husk, without recovering the dissolved sugars, onto cationic dye. The goal of the study was to investigate the implications of the alkali treatment on rice husk composition and structure and to compare its adsorption potential with rice husk ash. The effects of different concentrations of a base $(2 \%, 4 \%$, and $6 \%)$ and temperatures $\left(25^{\circ} \mathrm{C}, 70^{\circ} \mathrm{C}\right.$, and $\left.100^{\circ} \mathrm{C}\right)$ were considered. Surface modification was assessed utilizing Fourier transform infrared spectroscopy (FTIR) and scanning electron microscopy (SEM), followed by adsorption studies of malachite green using chemically modified rice husk (MRH) and rice husk ash (RHA). The results showed that even a mild treatment $(4 \% \mathrm{NaOH})$ produces visible changes in the topology and bond vibrations. Although similar trends were observed in the case of adsorbent MRH and RHA, adsorbent I (MRH) proved to be an efficient adsorbent as compared to adsorbent II (RHA). MRH and RHA followed the pseudo second-order of reaction. The $\mathrm{R}^{2}$ value for RHA (0.8619 and 0.838) and MRH (0.038 and 0.987) in Langmuir and Freundlich isotherms suggested that RHA follows the principle of monolayer, whereas MRH shows the heterogeneity of binding sites.
\end{abstract}

Keywords: bronsted base, rice husk, azo dye, equilibrium studies, kinetic studies

*e-mail: rahat.naseer@uvas.edu.pk 


\section{Introduction}

Rice is a staple food for one-third of the population. In developing countries, especially in Southeast Asia, rice production has seen a significant increase, as have rice husks. Rice husk ( $\mathrm{RH}$ ) enjoys low nutritional value due to less protein content and high silica and lignin content. The husk is considered a disposal problem and farmers usually burn them, contributing to an environmental problem [1]. Rice husks have many uses in practice, and one of them is use as an adsorbent, although the use of various plant/crop residues being eco- friendly became the focus of removing the environmental contaminants. However, the utilization of crop/plant residues has many drawbacks such as adsorption capacity, bulk requirement and their removal from the solution. To overcome these hurdles, many thermal or chemical modifications have been the focus of many researchers, with various chemicals used including $\mathrm{H}_{2} \mathrm{SO}_{4}, \mathrm{HCl}$, tartaric acid, $\mathrm{Na}_{2} \mathrm{HCO}_{3}, \mathrm{NaOH}$ and even water to increase the adsorption capacity of different plant parts [2]. Bronsted alkali also has the potential of modifying a cell wall, which is well documented. Alkali acts by two mechanisms: solvation and saponification. These two processes result in the swelling of biomass, which makes inner space and access an easy task [3]. Alkali treatments also reduce lignin partially. The other constituents of the cell wall, namely xylan and lignin, support its cellulosic backbone, forming a stable matrix. Although ammonia has been widely used for breaking lingo-cellulosic bonds, leading to environmental issues. In the present study, we used sodium hydroxide, which is inexpensive and much easier to handle than ammonia [4]. The waxed and tough outer surface of rice husk makes it a hard target for any organic and inorganic reaction. It is reported that chemical treatments can produce certain surface modifications that can upgrade their quality utilization [5]. Azo dyes are the largest group of chromophores used in the chemical industry. These dyes can be broken down into aromatic amines and arylamines, which are known carcinogens in humans and animals. Among azo dyes, Malachite green and its metabolites are very resistant and to removal of their residues from water systems [6]. Rice husk-based adsorbent has caught some attention, though, and a few studies have been conducted [7]. Still, its use is limited to the RHA - an expensive and laborious product of rice husk. Treatment of rice husk with organic and inorganic acids has been established to modify its properties by altering surface properties. The present work targets the development of simple low-cost alkali treatment to change the surface properties of rice husk for their subsequent use as an efficient adsorbent against cationic dyes as compared to rice husk ash or precipitated silica from the husk [8].

\section{Materials and Methods}

\section{Adsorbents and Their Sources}

Rice husk (RH) was obtained from the local threshing mill, washed with distilled water and dried at $70^{\circ} \mathrm{C}$ in a hot air oven for 72 hours. Dried husk was ground to mesh size $2 \mathrm{~mm}$ and stored in a polythene bag for further use. Adsorption studies were carried out using two rice husk-based adsorbents. Alkali-modified rice husk was our adsorbent I and abbreviated as $\mathrm{MRH}$ (chemically modified husk) prepared by soaking ground rice husk in $2 \%, 4 \%$ and $6 \%$ commercial-grade sodium hydroxide solution for 24 hours, and reagent loading was $10 \mathrm{~g} / 80 \mathrm{ml}$ at $273^{\circ} \mathrm{K}$ [9] (although only $4 \%$ was used to study adsorption kinetics). Rice husk ash (RHA) prepared from the same rice husk was our adsorbent II. $\mathrm{RH}$ was washed with distilled water repeatedly and kept in a muffle furnace at $700^{\circ} \mathrm{C}$ for 6 hours. Both the adsorbents and untreated rice husks were subjected to scanning electron microscopy (SEM) and FT/IR for topological alterations [10]. The Fourier transform infrared spectroscopy (FT/IR) procedure was done by using potassium bromide sample pellet on a 3:1 ratio. The order of 32 scans was given. Structural changes were dissected in the area of $600-4000 \mathrm{~cm}^{-1}$. This region is normally employed to cellulose. SEM microscopy was done using an electron microscope JSM 648 operated at $10 \mathrm{kV}$ under a low vacuum. Samples were devoid of any moisture content.
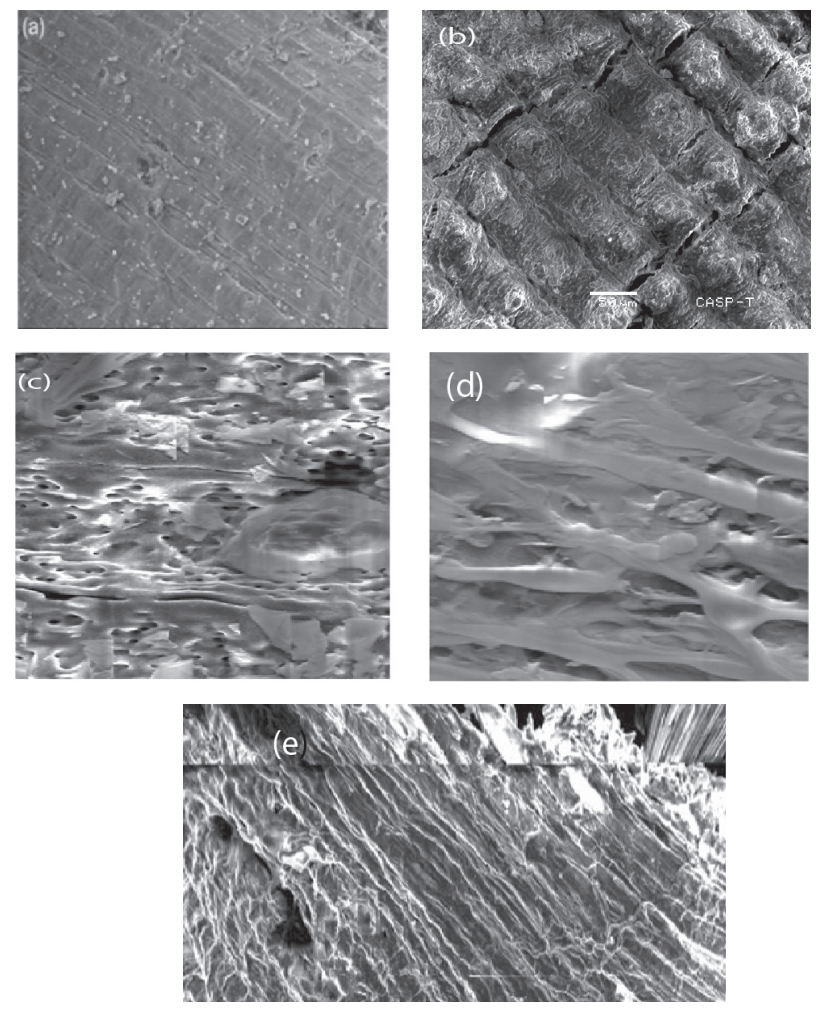

Fig. 1. a) untreated rice husk, b) 4\% alkali treated rice husk, c) rice husk ash, d) rice husk ash with adsorbed dye, e) 4\% alkali treated husk with adsorbed dye. 


\section{Adsorption Experiments and Equilibrium Studies}

In each experiment $0.5 \mathrm{~g}$ of each adsorbent and dye solution, $50 \mathrm{ppm}$ per $100 \mathrm{~mL}$ was added in $250 \mathrm{~mL}$ flasks and the mixture was stirred at $160 \mathrm{rpm}$ for various time intervals $(0,50,100,150,200 \mathrm{~min})$ maintaining $\mathrm{pH} 6$ at room temperature $\left(25^{\circ} \mathrm{C}\right)$. After each interval flasks (in triplicates) were centrifuged at $4000 \mathrm{rpm}$ for 10 minutes. The absorption of supernatant was measured spectrophotometrically as described by Vas Marcelo [11].

The influence of $\mathrm{pH}$ (from 2 to 12 with the interval of 2), temperature range (from $20^{\circ} \mathrm{C}$ to $80^{\circ} \mathrm{C}$ interval with $20^{\circ} \mathrm{C}$ ), adsorbent dose (from $0-25 \mathrm{~g}$ ) and effect of initial dye concentration was studied. Data thus obtained was used to elucidate reaction equilibrium and kinetic models.

\section{Results and Discussion}

The chemically modified rice husk (MRH) and rice husk ash (RHA) was analyzed for moisture dry matter and ash content. The bulk density and particle surface area was also estimated.

\section{Structural Characterization of Adsorbents}

\section{Fourier Transform Infrared Spectroscopy (FT-IR) and Scanning Electron Microscopy (SEM) Analysis}

FTIR and SEM analysis provided a detailed look into the topology and modifications of MRH and RHA. The micrograph of untreated rice husk shown in Fig. 1a) exhibited a smooth and even texture. Alkali-treated samples, on the other hand, showed surface modifications [12]. The cracks and bursting of the outer epidermis can be appreciably seen in Fig. 1b), comparatively more swollen than the untreated. Epidermis cracks are visible in alkali-treated husk [13], and silica distribution can also be visualized. The SEM results of RHA also showed clear large pores in Fig. 1c). The disrupted surface and porous Fig. 1c) texture can provide a suitable ground for the molecules to get adsorbed. This is evident from the micrographs of MRH and RHA after adsorption (Fig. 1d-e)) as all the cracks and pores are filled with dye as the number of binding surfaces increased.

These results were also supported by FT/IR analysis. The higher intensity band at $799 \mathrm{~cm}^{-1}$ indicated pretreatment. Treated samples showed reduced absorbance at $1033 \mathrm{~cm}^{-1}$ (Fig. 2). The absorption bands at 794, 1033, 1457, 1511, 1635, 2916, 3312, 3748 $798,1035,1457,1513,1637,2919,3312$, and $3750 \mathrm{~cm}^{-1}$ in the untreated rice husk samples correspond to the lignocellulosic region. The group frequencies are shown in Table 3, along with their respective roles.

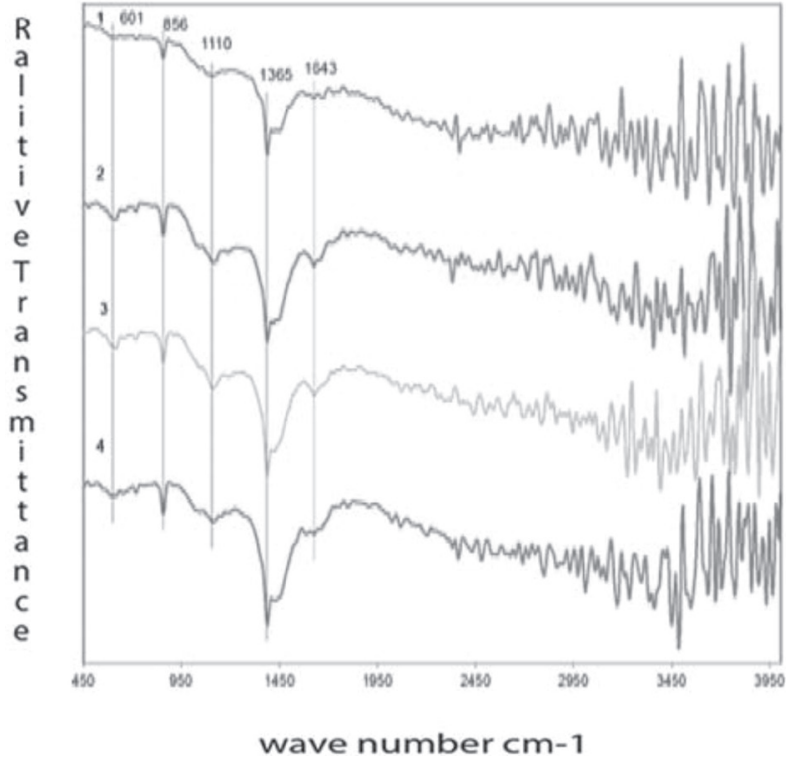

Fig. 2. Absorption spectrum: (1) untreated rice husk, (2) treated rice husk with $2 \%$ alkali solution, (3) treated rice husk with $4 \%$ alkali solution, and (4)treated rice husk with $6 \%$ alkali solution

The banding pattern shows the presence of a strong lignin carbohydrate matrix [14]. The absorption band at $1388 \mathrm{~cm}^{-1}$ in all treated samples corresponds to the irregular bending pattern of $\mathrm{CH}_{3}$ and $\mathrm{OCH}_{3}$ present in lignin. It was formerly studied that the outermost layer of rice husk is protected with pectin waxes along with other impurities. The hydrophobic nature of the waxes and lignin offer resistance in adsorption. Condition of temperatures and base treatment hydrolyze the defensive waxes from the outermost layer of the husk. The hemicellulose polymers with more branches have a stronger hydrophilic property and are dissolved more effectively in alkali media [15]. We concluded that high temperature, longer treatment and a higher concentration of alkali can expel the portion of the lignin content, though the lignin will not degrade at a lower temperature [16].

Moreover, degradation also reduces $\mathrm{C}-\mathrm{H}$ stretching at 2896 and $-\mathrm{OH}$ stretching at $3312 \mathrm{~cm}^{-1}$. The disappearance of absorption bands at $1457 \mathrm{~cm}^{-1}$ suggests some removal of lignin [17]. The difference of absorbance of treated and untreated samples in FTIR corresponds in the region ranges from $800-1513$ and $2995-4000 \mathrm{~cm}^{-1}$. The most distinct peak at $1388 \mathrm{~cm}^{-1}$ corresponds to the asymmetric bonding present in lignin, emphasizing the fact that rice husk has the highest lignin contact in agricultural residues. The peaks lie in the region corresponding to $\mathrm{C}-\mathrm{O}$ stretch vibration in cellulose, hemicellulose, and lignin of untreated husk showing a shift after the treatment $\left(617,725,1157,1141,2800,2969 \mathrm{~cm}^{-1}\right)$ has been shifted to disappearance in treated samples to $717,1133,1419,1434,2784$, and $2946 \mathrm{~cm}^{-1}$ repetitively (Fig. 2). This can be explained based on reagent diffusion into the rice husk, resulting in subsequent 
Table 1. Properties of rice husk-based adsorbents.

\begin{tabular}{|c|c|c|}
\hline Characteristics & Rice Husk & Rice husk ash \\
\hline Moisture \% & $9.80 \pm 1$ & $0.81 \pm 0.2$ \\
\hline Ash content \% & $15.19 \pm 1$ & $88 \pm 5$ \\
\hline Dry mass \% & $90.00 \pm 0.74$ & $99.19 \pm 0.8$ \\
\hline Bulk density $\mathrm{g} / \mathrm{cm}^{3}$ & $0.11 \pm 0.3$ & $0.93 \pm 0.4$ \\
\hline Surface area $\mathrm{m}^{2} / \mathrm{g}$ & $2342 \pm 148$ & $57.5 \pm 5.8$ \\
\hline
\end{tabular}

swelling. This will facilitate the disaggregation of the rice husk matrix and indicates the dissolution procedure, which was proceeded by considerable swelling of the rice husk matrix and then the swollen appearance of the husk.

\section{Functional Groups Make Adsorption Possible}

Silicon embedded in the matrix of cellulose constitute the outer surface of rice husk. This tough structure protects the rice grain from termites and microorganisms. This complex structure is present in neutral sites and hence favors less or transient adsorption. Therefore, alkali treatment of rice husk removes impurities and expresses various functional groups like hydroxyl, carboxyl, and amide groups [18]. Alkali treatment is reported to increase adsorption capacity and reduce equilibrium time [19]. RHA generally depends upon its large porosity for the adsorption or to some extent on its negatively charged $\mathrm{OH}$ groups, whereas alkali treatment is known to expose multiple functional groups.

\section{Effect of $p H$}

The impact of $\mathrm{pH}$ was checked on the adsorption of malachite green using both the adsorbents MRH and RHA. Although $\mathrm{pH}$ has a significant impact on adsorption, chemically modified husk is more efficient in terms of quantitative uptake. The change in $\mathrm{pH}$ can influence surface charges and promote the dissociation of functional groups on the surface [20]. We observed
Table 3. Absorption bands of treated and untreated rice husk $(\mathrm{SS} 1=$ untreated $\mathrm{RH}, \mathrm{SS} 2=$ treated $\mathrm{RH}$ with $2 \% \mathrm{NaOH}$, $\mathrm{SS} 3=$ treated RH with $4 \% \mathrm{NaOH}, \mathrm{SS} 4=$ treated $\mathrm{RH}$ with $6 \%$ $\mathrm{NaOH})$.

\begin{tabular}{|c|c|c|c|c|}
\hline Absorbance & SS1 & SS2 & SS3 & SS4 \\
\hline 794.53 & 70.8 & 60.48 & 62.99 & 57 \\
\hline 1033 & 61.5 & 47.49 & 52.73 & 49.38 \\
\hline 1457 & 41.6 & 25.9 & 28.9 & 21.36 \\
\hline 1511 & 49.05 & 39.18 & 42.17 & 34.44 \\
\hline 1635 & 51.98 & 41.96 & 43.4 & 42.3 \\
\hline 2916 & 39.65 & 38.9 & 35.7 & 36.7 \\
\hline 3312 & 45.39 & 31.38 & 33.45 & 33.83 \\
\hline 3748 & 46.29 & 0.0003 & 17.09 & 69.009 \\
\hline
\end{tabular}

that maximum adsorption of $98.3 \%$ takes place at $\mathrm{pH}$ 6-8. Adsorption will continue to show a rising trend with the rise in $\mathrm{pH}$ by reducing the competition between $\mathrm{H}^{+}$ions in the solution and dye cations. As the $\mathrm{pH}$ increases beyond 10, dye becomes self-saturated due to the formation of new species of dye. Hence for the kinetic studies, $\mathrm{pH} 6$ was considered suitable for both the adsorbents [21], and thus the $\mathrm{pH}$ range 6 to 8 can appreciate a better trend in the adsorption for treated rice husk, although non-significantly.

\section{Effect of Contact Time}

The impact of contact time on adsorption was studied for both adsorbents I and II, the time interval for shaking ranges from 0 to $180 \mathrm{~min}$. The rapid rate of adsorption was observed for adsorbent I (RF) in the first $60 \mathrm{~min}$, which gradually decreases up to 90 min and then equilibrium was attained. In the case of adsorbent II, the equilibrium was attained after $150 \mathrm{~min}$ and adsorption was gradual. The rapid onset of sorption can be explained due to the accessibility of the huge number of binding sites on the outside of adsorbents occupied with dye molecules slowing down it as reaction proceeds [22].

Table 2. Group frequencies of respective functional groups.

\begin{tabular}{|c|c|c|c|}
\hline $\mathrm{cm}^{-1}$ & Functional group & Corresponding vibration & Ref \\
\hline $800-950$ & $\mathrm{OH}$ & Free and hydrogen bonded OH-stretching & Labbe2005 \\
\hline $950-1035$ & $\mathrm{C}-\mathrm{H}$ & Stretching in cellulose 2008 \\
\hline $1035-1457$ & $\mathrm{OH}$ & H bonding vibration due to water molecule & Hurtubise Krassing 1960 \\
\hline $1457-1513$ & $\mathrm{C}=\mathrm{C}$ & Aromatic stretch in lignin & Hsu.T 2010 \\
\hline $1513-1637$ & $\mathrm{C}-\mathrm{H}$ & Irregular bending present in $\mathrm{CH}_{3}$ and $\mathrm{O}_{-} \mathrm{CH}_{3}$ present in lignin & Liu 2007 \\
\hline $1637-2919$ & $\mathrm{C}-\mathrm{O}$ & $\mathrm{C}-\mathrm{O}$ stretch vibration in $\mathrm{OH}$, cellulose and hemi cellulose in lignin & Lee 2009 \\
\hline $2919-4000$ & $\mathrm{C}-\mathrm{H}$ & Malformation vibration in cellulose & Ang 2012 \\
\hline
\end{tabular}




\section{Effect of Dose of Adsorbent}

Adsorbent dose showed a remarkable influence on the sorption process. It also signifies the dual challenge because a large number of adsorbents can also present a disposal problem. In the present study adsorbent dosage on malachite green adsorption was investigated in the range of $5-20 \mathrm{~g} / \mathrm{L}$. Chemically modified rice husk $(\mathrm{MRH})$ can remove $98.87 \%$ dye and in the case of rice husk ash (RHA), the removal is $92.73 \%$. Adsorption is the function of the binding sites available on the surface, therefore the amount of adsorbent required in the case of MRH is less than RHA. There is a reason to believe that chemical modifications increase the number of binding sites, also supported by other studies [23].

\section{Effect of Temperature}

A solution with fixed dye concentration and adsorbent dose incubated at different temperatures is evenly spaced between $30^{\circ} \mathrm{C}$ to $60^{\circ} \mathrm{C}$. The temperature has an inverse effect on adsorption capacity (Fig. 3). The variation in the adsorbent constant is difficult to study due to small data. The behavior of two adsorbents is significantly different because RHA is already a hightemperature product. This finding is in accord with the consequences of [24] increased kinetic energy, which overcomes the adsorbent and adsorbate interaction.

\section{Effect of Dye Concentration}

The initial dye concentration effect was studied at fixed temperature of $30^{\circ} \mathrm{C}$ and $\mathrm{pH} 6$, while dye concentration varied from 10 to $100 \mathrm{mg} / \mathrm{l}$. As the concentration of initial dye is raised, adsorption capacity also increases as it makes a driving force and this thrust beats mass transfer resistance of dye between the solid phase and aqueous phase. In this manner, the percentage of dye removal increases incrementally up to $95.31 \%$. Both adsorbents contain definite active sites, hence instant saturation occurs at a specific concentration. This proportionality between the dye and absorbent is
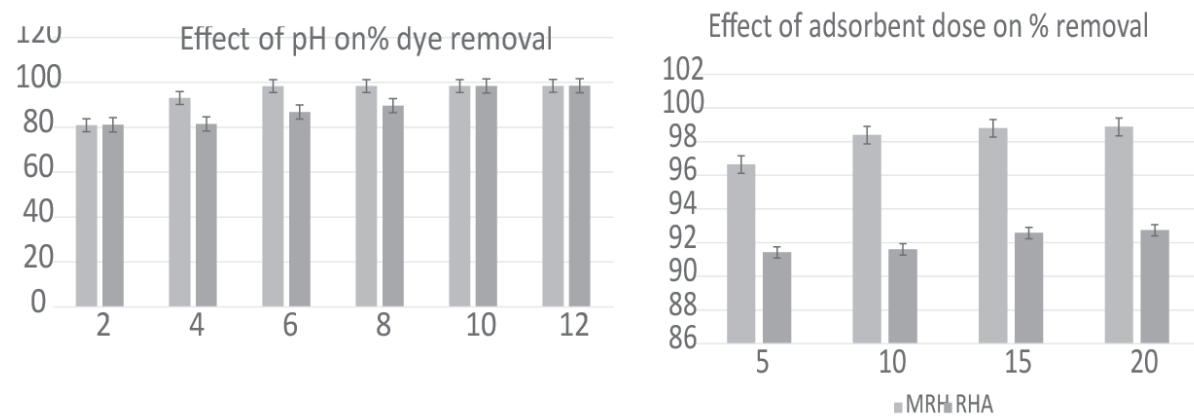

$\llbracket \mathrm{MRH} R H \mathrm{RH}$
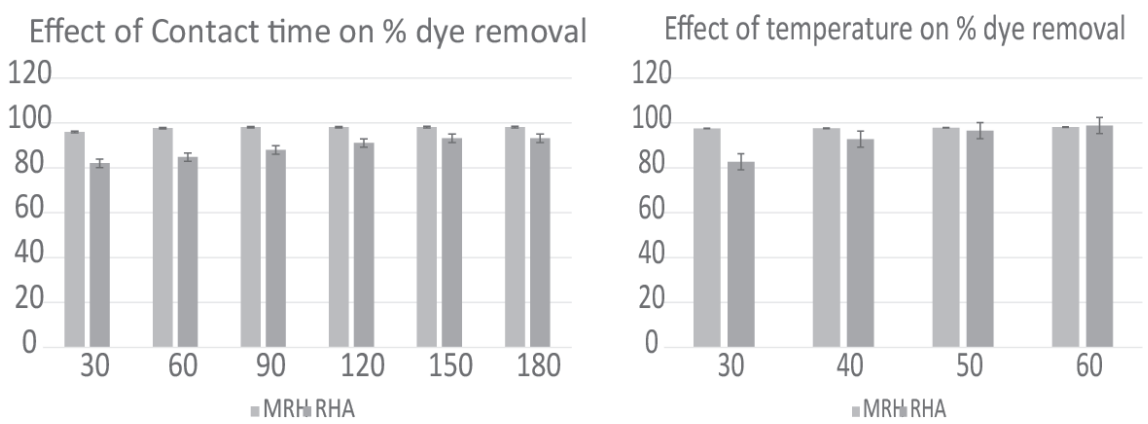

Effect of initial dye concentration on \% rem

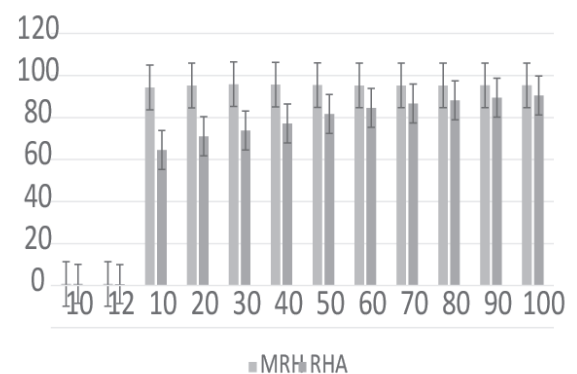

Fig. 3. Effect of different parameters on adsorption. 
Table 4. Comparative values of two isotherms.

\begin{tabular}{|c|c|c|c|c|c|c|c|c|c|}
\hline \multirow[b]{2}{*}{ Dye } & \multicolumn{4}{|c|}{ Langmuir model } & \multirow{2}{*}{$\begin{array}{l}\text { Experimen tal value } \\
\qquad \mathrm{q}_{\max }(\mathrm{mg} / \mathrm{g})\end{array}$} & \multicolumn{4}{|c|}{ Freundlich model } \\
\hline & Adsorbent & $\begin{array}{c}\mathrm{q}_{\mathrm{e}} \\
(\mathrm{mg} / \mathrm{g})\end{array}$ & $\begin{array}{c}\mathrm{K}_{\mathrm{L}} \\
\mathrm{L} / \mathrm{mg}\end{array}$ & $\mathrm{R}^{2}$ & & $1 / \mathrm{n}$ & $\begin{array}{c}\mathrm{K}_{\mathrm{F}} \\
(\mathrm{mg} / \mathrm{mg})\end{array}$ & $\mathrm{R}^{2}$ & $\begin{array}{c}\mathrm{q}_{\mathrm{e}} \\
(\mathrm{mg} / \mathrm{g})\end{array}$ \\
\hline & Rice husk & 1666.667 & 0.011765 & 0.038 & 95.31345 & 0.9472 & 0.060034 & 0.9876 & 0.259318 \\
\hline & RHA & 14.8368 & 0.083292 & 0.8619 & 90.50673 & 0.3488 & 2.266209 & 0.838 & 4.968469 \\
\hline
\end{tabular}

also attributed to the enhanced interaction between the dye and absorbent sites. Adsorption capacity increased the concentration of dye, generating a driving force that minimizes the resistance of mass transfer between two physically distinct phases, hence increasing adsorption up to $95.31 \%$. Current results are similar to the findings of other researchers [25].

\section{Kinetic Modeling}

Kinetic modeling of equilibrium data gave better insight into the bio-sorption behavior and performance of adsorbents. This was done to find the minimum necessary time to achieve equilibrium.

The pseudo second-order chemisorption kinetic rate equation is:

$$
\frac{d Q t}{d t}=k(Q e-Q t)^{2}
$$

Elucidation of the kinetic mechanism was done for the sorption system of MG. For ordered kinetics, the Lagergren equation is widely used for first-order kinetics. When plotted, $\log \left(\mathrm{q}_{\mathrm{e}}-\mathrm{q}_{\mathrm{t}}\right)$ against the time in batch studies showed that the Lagergren equation failed to predict the experimental adsorption capacity $\left(\mathrm{q}_{\text {exp }}\right)$, which is $(49.07 \mathrm{mg} / \mathrm{g}$ for MRH), and 46.577 for RHA as compare to $\mathrm{q}_{\mathrm{e}}$ (Table 5). Hence the first-order equation is not best fitted with the sorption data of both the adsorbents.

In the case of adsorbent $1(\mathrm{MRH})$, as the available binding sites are numerous, the increased concentration of dye generates a driving force. The rate of adsorption of MRH is significantly higher than RHA at the start of the reaction due to a large number of binding sites on MRH.

In the pseudo second-order equation, the adsorption rate is the function of the square of the available binding sites. This model is represented linearly, where $\mathrm{q}_{\mathrm{e}}$ (49.26 mg/g for MRH and $48.54 \mathrm{mg} / \mathrm{g}$ for RHA) is in agreement with that of $\mathrm{q}_{\text {exp }}$. Hence the sorption parameters, in this case, can be best clarified by a pseudo second-order equation for both the adsorbents.

\section{Equilibrium Modeling}

Equilibrium modeling helped us in the determination of the adsorption mechanism. Freundlich and Langmuir's isotherms were used to correlate experimental data. These isotherms help us to understand the characteristics and mechanisms involved in adsorption. For the equilibrium, studied fixed biomass was taken [26].

\section{Langmuir Isotherm}

According to the Langmuir adsorption model, adsorbate behavior is similar to an ideal gas at isothermal conditions. The theoretical Langmuir isotherm equation is shown as:

$$
\mathrm{qe}=\frac{\mathrm{qmKLCe}}{(1+\mathrm{KLCe})}
$$

The linear form of the above mention equation is:

$$
\frac{1}{\mathrm{qe}}=\left(\frac{1}{\mathrm{qm}}\right)+\left(\frac{1}{\mathrm{KL} \mathrm{qmCe}}\right)
$$

\section{Freundlich Isotherm}

This is empirical isotherm for showing isothermal changes of adsorption for a given amount by a unit mass of adsorbent with pressure.

$$
\mathrm{qe}=\operatorname{KFCe}(1 / \mathrm{n})
$$

The above equation represents the connection between sorption capacity and intensity. Generally, two

\begin{tabular}{|c|c|c|c|c|c|c|c|c|}
\hline \multirow[b]{2}{*}{ Dye } & \multirow[b]{2}{*}{ Nano sorbent } & \multicolumn{3}{|c|}{ Pseudo first order } & \multirow{2}{*}{$\underset{(\mathrm{mg} / \mathrm{g})}{\mathrm{q}_{\exp }}$} & \multicolumn{3}{|c|}{ Pseudo second order } \\
\hline & & $\begin{array}{c}\mathrm{q}_{\mathrm{e}} \\
(\mathrm{mg} / \mathrm{g})\end{array}$ & $\begin{array}{c}\mathrm{K}_{1 \mathrm{ad}} \\
(\mathrm{min})^{-1}\end{array}$ & $\mathrm{R}^{2}$ & & $\begin{array}{c}\mathrm{q}_{\mathrm{e}} \\
(\mathrm{mg} / \mathrm{g})\end{array}$ & $\begin{array}{c}\mathrm{K}_{2 \mathrm{ad}} \\
(\mathrm{min})^{-1}\end{array}$ & $\mathrm{R}^{2}$ \\
\hline & Rice husk & 4.114338 & 0.009336 & 0.9543 & 49.07 & 49.26108 & 0.033778 & 1 \\
\hline & RHA & 11.07643 & 0.00343 & 0.9379 & 46.57783 & 48.54369 & 0.002785 & 0.9993 \\
\hline
\end{tabular}
parameters are directly proportional. The adsorption intensity $1 / \mathrm{n}$ is also reflective of adsorption feasibility.

Table 5. Reaction orders of modified rice husk and rice husk ash. 
The linearity of the terms can be achieved when shown as $\log$ function.

$$
\log \mathrm{qe}=\log \mathrm{KF}+(1 / \mathrm{n}) \log \mathrm{Ce}
$$

Adsorption isotherms show the relationship between adsorption capacity and concentration at equilibrium at a constant temperature. The relationship was studied using a varied concentration of $\mathrm{MG}$ while keeping the other constant. As the philosophy of Langmuir isotherm suggests, a uniformity of energy of finite binding sites, hence ligands, can interact with the binding sites only and no interaction between the ligands is possible. So we assume that adsorption follows the principle of a monolayer. Linearity was exhibited for MRH and RHA with respected $\mathrm{R}^{2}$ values of 0.038 and 0.8619 (Table 4) respectively. RHA calculated monolayer capacity $\left(\mathrm{q}_{\max }\right)$ agrees with the experimental one, suggesting that the Langmuir equation is suitable for explaining the behavior of RHA. The same results have been reported by [27]. On the other hand, Freundlich isotherm explains the heterogeneity in binding sites, which allows for the interaction of ligand not only with binding sites but also with one another. The $\mathrm{R}^{2}$ values for modified rice husk (MRH) are 0.9876 and for rice husk ash (RHA) 0.838. The values suggest Freundlich as a good model for MRA rather than ash. Hence we can conclude that both isotherms can explain the behavior of RHA to some extent, and for chemically modified rice husk, the Freundlich isotherm described the adsorption well.

\section{Conclusions}

This study showed that mild treatment of rice husk with sodium hydroxide can alter the surface structure significantly, although little changes in the chemical composition ratio took place. The shifting banding pattern also showed structural argumentation. Besides, the study demonstrates that chemically altered rice husk and rice husk ash can go about as potential adsorbents to eliminate MG dye. Adsorption is a highly $\mathrm{pH}$-dependent process. The Freundlich isotherm model is suitable for altered rice husk, whereas the Langmuir isotherm model is for rice husk ash (RHA) showing monolayer capacity. In both cases, adsorption obeyed the pseudo secondorder reaction. However, chemically modified rice husk (MRH) exhibits more adsorption potential than rice husk ash (RHA) due to the heterogeneity of binding sites. The suggested treatment is constructive for the conversion of rice husk into a value-added product.

\section{Acknowledgements}

We are thankful to the Punjab Agricultural Research Board for funding this research. we are also thankful to Dr.Tausoif Hussain, assistant professor at the Center of Advanced Studies for Physics, GCU Lahore for his technical support.

\section{Conflict of Interest}

The authors declare no conflict of interest.

\section{References}

1. LIM J.S., ZAINUDDIN A.M., ALWI W., RAFIDAH S., HASLENDA S., A review on utilization of biomass from rice industry as a source of renewable energy. Renew. Sustain. Energy Rev. 16, 3084, 2012.

2. ACHARYA J., KUMAR U., MUHAMMED P.R., Removal of heavy metals from wastewater by chemically modified agricultural waste material as potential adsorbent-A review.IJCET. 8, 526, 2018.

3. BAZARGAN A., GEBREEGZIABHER T., HUI C.W., MCKAY G., The effect of alkali treatment on rice husk moisture content and drying kinetics. Biomass and Bioenergy. 70, 468, 2014.

4. SELIM A.S.M., PAN J., TAKANO T., SUZUKI T., KOIKE S., KOBAYASHI Y., TANAKA K. Effect of ammonia treatment on physical strength of rice straw, distribution of straw particles and particle-associated bacteria in sheep rumen. Anim. Feed Sci. Technol. 115, 117, 2004.

5. ISA K.M., DAUD S., HAMIDIN N., ISMAIL K., SAAD S.A., KASIM F.H., Thermogravimetric analysis and the optimization of bio-oil yield from fixed-bed pyrolysis of rice husk using response surface methodology (RSM). Industrial Crops and Products. 33, 481, 2011.

6. YONGMEI MA., MAOFEI NI., SIYUE LI. Optimization of Malachite green removal from water by $\mathrm{TiO}_{2}$ nanoparticles under UV irradiation. Nano materials (Basel). 8 (6), 428, 2018.

7. UPENDRA K., MANAS B. Sorption of Cadmium from aqueous solutions using pretreated rice husk. Bio-resource Technology. 97, 104, 2006.

8. CHANDRAKANT T., VIMAL C., SRIVASTAVA I., AJAY D.H. Modeling of binary isotherm behavior for the adsorption of Catechol with phenol and resorcinol onto rice husk ash. Indian chemical engineer. 59, 312, 2017.

9. SAHA P., CHOWDHURY S., GUPTA S., KUMAR I. Insight into adsorption equilibrium, kinetics, and thermodynamics of Malachite Green onto clayey soil of Indian origin. Chem. Eng. J. 165, 874, 2010.

10. FATIHATUL N., AHMMED S., IBRAHEM KAMARIAH N. Comparative Study of Single and Multi-layered Fixed Bed Columns for the Removal of Multi-metal Element using Rice Husk Adsorbents J. Applied Sci. 14, 1234, 2014.

11. VAZ MG., PEREIRA AG., FAJARD AR., AZEVEDO A.C., RODRIGUES F.H. Methylene blue adsorption on chitosan-g-poly (acrylic acid)/rice husk ash superabsorbent composite: Kinetics, equilibrium, and thermodynamics. Water Air, Soil Pollution, 228,14, 2017.

12. COATES J.S.S. Interpretation of infrared spectra, A practical approach. Encyclopedia of Analytical Chemistry R.A. Meyers (Ed.) 10815, 2000.

13. ANG T.N., NGOH G.C., CHUA A.S.M., LEE M.G. Elucidation of the effect of ionic liquid pretreatment on rice husk via structural analyses. Biotechnol Biofuels. 5, 67, 2012. 
14. NDAZI B.S., NYAHUMWA C.W., TESHA J. Chemical and thermal stability of rice husks against alkali treatment. BioResources. 3, 1267, 2008.

15. SRIVASTAVA V.C., MALL I.D., MISHRA I.M. Characterization of mesoporous rice husk ash (RHA) and adsorption kinetics of metal ions from aqueous solution onto RHA. Journal of hazardous materials, 134, 257, 2016.

16. CHUNG Y.Y.Production of higher heating values of biomass from proximate and ultimate analyses. Fuel. 9, 1128, 2011.

17. UPTON BRIANNA M., ANDREA M. K. Strategies for the conversion of lignin to high-value polymeric materials: review and perspective. Chemical reviews. 116, 2275, 2015.

18. CHOWDHURY S., MISHRA R., SAHA P., KUSHWAHA P. Adsorption thermodynamics, kinetics and isosteric heat of adsorption of malachite green onto chemically modified rice husk. Desalination. 265, 159, 2011.

19. SARTAPE A.S., MANDHARE A.M., JADHAV V.V., RAUT P.D., ANUSE M.A., KOLEKAR S.S. Removal of malachite green dye from aqueous solution with adsorption technique using Limonia acidissima (wood apple) shell as low-cost adsorbent. Arabian Journal of Chemistry. 10, 3229, 2017.

20. FARNANE M., TOUNSADI H., ELMOUBARKI R., MAHJOUBI F.Z., ELHALIL A., SAQRANE S., ABDENNOURI M., QOURZAL S., BARKA N.Alkaline treated carob shells as sustainable biosorbent for clean recovery of heavy metals: Kinetics, equilibrium, ions interference and process optimisation.Ecological Engineering. 101, 9, 2017.

21. CHAKRABORTY S., CHOWDHURY S., SAHA PD. Adsorption of crystal violet from aqueous solution onto $\mathrm{NaOH}-$ modified rice husk. Carbohydrate Polymers. 86, 1533, 2011.
22. LOTFI M., LAZHAR B., JEAN-CLAUDE B., ABDELKRIM B., AYMEN A., AMAR T., FARID D., KHODIR M., HOUCINE R.Removal of Methylene Blue from aqueous solutions by adsorption on Kaolin: Kinetic and equilibrium studies.Applied Clay Science. 153, 38, 2018.

23. JIAYANG L., ZHIXIN W., HONGYAN L., CHANGWEI H., PAUL R., QINGGUO H., Effect of solid state fermentation of peanut shell on its dye adsorption performance.Bioresource Technology. 249, 307, 2018.

24. SRIVASTAVA V.C., MALL I.D., MISHRA I.M. Adsorption thermodynamics and isosteric heat of adsorption of toxic metal ions onto bagasse fly ash (BFA) and rice husk ash (RHA). Chemical Engineering Journal. 132, 267, 2007.

25. LI C., KNIERIM B., MANISSERI C., ARORA R., SCHELLER H.V., AUER M., VOGEL KP., SIMMONS B.A., SINGH S. Comparison of dilute acid and ionic liquid pretreatment of switchgrass: biomass recalcitrance, delignification, and enzymatic saccharification. Bioresource Technol. 101, 4900, 2010.

26. KAYAL N., SINGH N. The quantitative estimation of silica in rice husk as by titrimetric method: A case study for uncertainty calculation. Journal of Metrology Society of India. 25, 115, 2010.

27. AFROZE S., SEN T. K., ANG M., NISHIOKA H. Adsorption of methylene blue dye from aqueous solution by novel biomass Eucalyptus sheathiana bark: equilibrium, kinetics, thermodynamics and mechanism. Desalination and Water Treatment. 57, 5858, 2016.

28. LAKSHMI U.R., SRIVASTAVA V.C., MALL I.D., LATAYE D.H. Rice husk ash as an effective adsorbent: Evaluation of adsorptive characteristics for Indigo Carmine dye. Journal of Environmental Management. 90, 710, 2009. 